\title{
Efficacy of thigh volume ratios assessed via stereovision body imaging as a predictor of visceral adipose tissue measured by magnetic resonance imaging
}

\author{
Jane J Lee, Jeanne H Freeland-Graves, M Reese Pepper, Wurong Yu, and Bugao Xu \\ The University of Texas at Austin (JJL, JFG, MRP, WY, BX), Department of Nutritional Sciences \\ (JJL, JFG, MRP), School of Human Ecology (WY, BX)
}

\begin{abstract}
Objectives-The research examined the efficacy of regional volumes of thigh ratios assessed by stereovision body imaging (SBI) as a predictor of visceral adipose tissue measured by magnetic resonance imaging (MRI). Body measurements obtained via SBI also were utilized to explore disparities of body size and shape in men and women.
\end{abstract}

Method-121 participants were measured for total/regional body volumes and ratios via SBI and abdominal subcutaneous and visceral adipose tissue areas by MRI.

\begin{abstract}
Results-Thigh to torso and thigh to abdomen-hip volume ratios were the most reliable parameters to predict the accumulation of visceral adipose tissue depots compared to other body measurements. Thigh volume in relation to torso [odds ratios (OR) 0.44] and abdomen-hip (OR 0.41 ) volumes were negatively associated with increased risks of greater visceral adipose tissue depots, even after controlling for age, gender, and body mass index (BMI). Irrespective of BMI classification, men exhibited greater total body $(80.95 \mathrm{~L}$ vs. $72.41 \mathrm{~L})$, torso $(39.26 \mathrm{~L}$ vs. $34.13 \mathrm{~L})$, and abdomen-hip (29.01L vs. $25.85 \mathrm{~L}$ ) volumes than women. Women had higher thigh volumes (4.93L vs. $3.99 \mathrm{~L})$ and lower-body volume ratios [thigh to total body (0.07 vs. 0.05$)$, thigh to torso (0.15 vs. 0.11$)$, and thigh to abdomen-hip (0.20 vs. 0.15$) ; p<0.05]$.
\end{abstract}

Conclusions-The unique parameters of the volumes of thigh in relation to torso and abdomenhip, by SBI were highly effective in predicting visceral adipose tissue deposition. The SBI provided an efficient method for determining body size and shape in men and women via total and regional body volumes and ratios.

\section{Keywords}

Thigh volume; stereovision body imaging; visceral adipose tissue

\footnotetext{
Corresponding Author and Reprint Request Contact: Jeanne H Freeland-Graves, PhD, RD, FACN, Bess Heflin Centennial Professor, Department of Nutritional Sciences, The University of Texas at Austin, 1 University Station, A2703, Austin, TX 78712, Tel: +1 512 471 0657, Fax: +1 512471 5844, jfg@ mail.utexas.edu.

Disclosure: The authors have no conflict of interest to declare.
} 


\section{INTRODUCTION}

Obesity is a significant public health concern associated with hypertension, dyslipidemia, coronary heart disease, and type 2 diabetes (Kurukulasuriya et al., 2011; Franssen et al., 2011; Logue et al., 2011; Nguyen et al., 2011). In the United States, approximately one-third of the population is overweight (33.3\%) and one-third is obese (34.9\%) (National Center for Health Statistics, 2013). At present, body mass index (BMI) is the most commonly used technique to assess obesity in populations due to its simplicity. Yet, this method is crude, in that body weight and height only estimate overall obesity, without consideration of the distribution of body fat (Bergman et al., 2011).

Generally, fat depots are classified as subcutaneous and visceral adipose tissue areas (Despres et al., 2008). Within the abdominal area, visceral adipose tissue is the more metabolically active depot due to its associations with escalated risks of cardiovascular disease, diabetes, and metabolic syndrome; whereas, subcutaneous adipose tissue is linked with lower health risks (Despres and Lemieux, 2006; Despres et al., 2008; Fox et al., 2007; Hayashi et al., 2008; Preis et al., 2010). Since visceral adipose tissue is more of a primary concern than is subcutaneous, this research explored the relationships between visceral adipose tissue determined by magnetic resonance imaging (MRI) and body volume measurements estimated by three-dimensional (3D) stereovision body imaging (SBI).

Lower body factors (thigh circumference, thigh fat, leg fat, leg to trunk fat ratio, sagittal abdominal diameter to thigh circumference ratio) have been shown previously to have favorable effects on normal insulin and glucose levels (Goodpaster, Thaete and Kelley, 2000; Snijder et al., 2004; Aasen et al., 2009; Park et al., 2012), metabolic dysfunction (Van Pelt et al., 2005; Heitmann and Frederiksen, 2009; Peppa et al., 2013), and risks of cardiovascular disease (Van Pelt et al., 2002; Heitmann and Frederiksen, 2009; Smith et al. 2005). Higher values of lower body factors have been suggested to exhibit protective effects on health risks associated with obesity-related diseases (Peppa et al., 2013; Park et al., 2012; Heitmann and Frederiksen, 2009). It is predicted that lower body components, such as thigh volume in relation to total body, trunk, or abdomen-hip would be linked negatively with the accumulation of visceral adipose tissue.

To date, instruments that measure regional adiposity, such as dual-energy x-ray absorptiometry (DXA), computed tomography (CT), and MRI, are restricted in field settings due to their bulkiness, cost, and/or radiation exposure. An innovation of this research is the use of a 3D SBI system to collect body measurements in a rapid and inexpensive manner. This device provides a visual presentation and quantitative values of human body size and shape, including volumes of total body, torso (lower neck to top of pelvis), abdomen-hip (smallest point of waist to crotch), and thigh (crotch to top of knee) (Figure 1). Previously, body volume measured via this system showed strong agreement with air displacement plethysmography (ADP) $\left(\mathrm{R}^{2}>0.99, p<0.01\right)$. No significant differences were found between these methods (mean difference $-0.17, p>0.05$ ), indicating the preciseness of this technique (Xu et al., 2009). Also, measurements were highly reproducible, with intraclass correlation coefficient and coefficient of variation values lower than 0.99 and 1.9, respectively (Xu et 
al., 2009). In the present research, unique body volume measurements derived via SBI were utilized to assess the association with visceral adipose tissue.

Stereotypically, men accumulate more fat in the abdominal region, which is characterized by an android or apple shape; whereas, women have greater fat deposits in the gluteal-femoral area, and exhibit a gynoid or pear-shaped body type (Haslam, Sattar and Lean, 2006; Cornier et al., 2011). Thus, men and women were assessed by SBI to document precise disparities in their body size and shape. Because central fat depots increase with age, especially for women with postmenopausal status (Haarbo et al., 1991; Reubinoff et al., 1995; Toth et al., 2000; Kanaley et al., 2001), demographics were taken into account for the examination of possible relationships between body volume measurements and obesity measures [overall obesity measures (BMI, percent body fat), abdominal adipose tissue areas (subcutaneous, visceral)].

\section{METHOD AND PROCEDURES}

\section{Study Design}

A total of 121 non-Hispanic white and Hispanic men $(n=67)$ and women $(n=54)$ made two visits to the University of Texas at Austin SBI laboratory and the MRI Imaging Research Center. Subjects were instructed to fast for 4 hours prior to the visit and avoid excessive perspiration, heavy exercise, and caffeine or alcohol for 10 hours.

Demographic and health history questionnaires were administered at visit 1. Participants were measured for body size and shape by anthropometrics, including height, weight by a scale and a stadiometer; body circumferences (waist, hip) and total/regional body volumes by SBI; and total percent body fat by ADP within 3 hours. At visit 2, MRI scans of the abdominal area were obtained for central obesity assessment within 5 days of the anthropometric measurements.

\section{Subjects}

Healthy non-Hispanic white and Hispanic men and women, aged 18 to 65 years with a BMI range of 18.5 to $40 \mathrm{~kg} / \mathrm{m}^{2}$ were recruited via notices posted online and on bulletin boards, and through word-of-mouth. Prescreening over the phone was performed before the first study visit. Criteria for exclusions were metallic/electronic implants or heavy metal ink tattoos, having known diseases, or being pregnant or breastfeeding. The risks and benefits of the study were explained and informed consents were obtained. The University of Texas at Austin Institutional Review Board approved this study.

\section{Anthropometrics}

Participants were measured for weight and height, wearing light clothing and barefoot, by an electronic scale (Tanita, Arlington, IL) to the nearest $0.1 \mathrm{~kg}$ and a stadiometer (Health o meter, South Shelton, CT) to the nearest $0.1 \mathrm{~cm}$, respectively. BMI was calculated as weight in $\mathrm{kg}$ divided by height in $\mathrm{m}^{2}$ and classified as healthy weight $\left(18.5-24.9 \mathrm{~kg} / \mathrm{m}^{2}\right)$, overweight (25-29.9 kg/m²), obese class I (30-34.9 kg/m²), or obese class II $\left(35-40 \mathrm{~kg} / \mathrm{m}^{2}\right)$. A MyoTape body tape (AccuFitness, Greenwood Village, $\mathrm{CO}$ ) measured body 
circumferences. Waist circumference was measured at the top of the iliac crest across the belly button and hip circumference was assessed at the widest extension of the buttocks. Anthropometric assessments followed standard protocols for anthropometric measurements (National Health and Nutrition Examination Survey III, 1988).

\section{Stereovision Imaging System}

A 3D SBI measured body size and shape of the participants (Xu et al., 2009; Lee et al., 2014). The SBI is capable of creating a 3D body image that can be rotated 360 degrees in all directions by employing the techniques of optical triangulation via four cameras and two projectors in front of and behind the subject, respectively (Lee et al., 2014). Four ultrashort throw NEC 575VT LCD projectors (NEC Corporation, Tokyo, Japan) illuminate the subject's body in order to generate artificial texture on the scanned surface, while four pairs of monochromatic CMOS cameras (Videre Design, Menlo Park, CA) capture the body image (Xu et al., 2009). The IEEE 1394 Firewire linked the SBI system to the host computer to transfer the texture pattern of the subject via a video graphics array hub. More detailed information regarding the instrument was reported previously by Xu et al. (2009) (Xu et al., 2009) and Lee et al. (2014).

Subjects were instructed to wear minimal tight underwear and a swimming cap during the assessment. A blindfold was provided to protect the subjects' eyes from the bright light emanating from the projectors. During acquisition, participants posed with their legs slightly spread and arms extended from the torso while holding their breath for one second. A total of ten body scans of 200 milliseconds each was completed for the subjects.

Body volume measurements assessed via SBI included total body, torso (lower neck to top of pelvis), abdomen-hip (smallest point of waist to crotch), and thigh (crotch to top of knee). Figure 1 shows the body image and regional body volumes assessed by SBI according to BMI classification. Subsequently, body volume ratios that reflect upper-(torso/total body, abdomen-hip/total body, abdomen-hip/torso) and lower-body volume ratios (thigh/total body, thigh/torso, thigh/abdomen-hip) were computed. The measurement descriptions of waist and hip circumferences by SBI were identical to the tape measurements. A SBI waistto-hip ratio measurement was computed by waist circumferences $(\mathrm{cm})$ divided by hip circumferences $(\mathrm{cm})$.

\section{Magnetic Resonance Imaging}

The evaluation of abdominal adipose tissue areas was performed using FDA-approved pulse sequences via a MRI 3.0 T General Electric scanner (GE Healthcare, Milwaukee, WI) by a certified MR technician. A 3-plane localizer scan was performed while centering the iliac crest after the subject was positioned on the magnet. A coronal slice was obtained as TR 140, TE 2.1, flip angle $80^{\circ}$, slice thickness $8.0 \mathrm{~mm}$ with gap $5.0 \mathrm{~mm}$, FOV $40 \times 40$, matrix $512 \times 93$, and bandwidth $62.5 \mathrm{kHz}$, while centering at the navel. The umbilicus coronal slice was analyzed for assessment of subcutaneous and visceral adipose tissue areas via SliceOmatic 4.3 (Tomovision, Montreal, CAN). Total abdominal adipose tissue area was computed by adding the areas of subcutaneous and visceral adipose tissue. Operation of the MRI scanner and maintenance of all the safety elements were performed only by imaging 
research center approved personnel. The term adiposity is defined as the total amount of adipose tissue, including lipids of adipose tissue, bone, nervous tissue and structural lipids from membranes. Thus, the term adipose tissue was used to indicate the fat mass quantified by MRI.

\section{Air Displacement Plethysmography}

Percent fat mass and fat-free mass were calculated from body mass, density, and volume, as determined by a BOD POD ${ }^{\circledR}$ body composition tracking system (Life Measurement System, Concord, CA). The body percent fat assessed by ADP was used as an overall obesity measure in this study to compare the relationship with central obesity measures (subcutaneous and visceral adipose tissue) in relation to total and regional body volumes and volume ratios. Moreover, the association between total/regional body volumes and percent body fat, according to BMI classification was explored. Body fat percentage assessed by BOD POD (or ADP) is based on the two-compartment model that the human body is composed of fat and fat-free mass, with the density of fat and fat-free mass are defined as $0.9 \mathrm{~kg} / \mathrm{L}$ and $1.1 \mathrm{~kg} / \mathrm{L}$, respectively (Collins et al., 2004). Participants were instructed to wear minimum clothing and cover their hair with a swimming cap to reduce error variance. Weights were measured by electronic scale and subjects were seated inside the sealed chamber. Under the isothermal conditions, body density was estimated via variations in pressure and body volume. The breathing circuit system measured thoracic gas volume while subjects breathed normally. Five prediction equations (Siri, Schutte, Ortiz, Brožek, Lohman) were available in the BOD POD ${ }^{\circledR}$ software in order to accurately measure body fat percentage for different populations, including the general population (Siri, 1961), African American men (Schutte et al., 1984), African American women (Ortiz et al., 1992), lean and obese individuals (Brožek et al., 1961), and children aged under 17 years old (Lohman, 1986). These prediction equations were based on measurements of body volume and body mass to estimate fat and fat-free mass.

\section{Statistical Analysis}

Statistical analyses were performed independently in men and women due to the gender differences in total and regional fat distribution. The normality of the distributions of the variables was examined by the Kolmogorov-Smimov test (Massey, 1951). Overall characteristics of the participants were described as mean and standard error of the mean (Table 1).

The odds ratios (OR) were computed via multinomial logistic regression analysis to predict of the risks of being in the low tertile of visceral adipose tissue versus middle or high, with one standard deviation increases in total/regional body volume parameters (Table 2).

Analyses were preceded with no adjustment (model 1); adjusted for age and gender (model 2); adjusted for BMI group (model 3); and adjusted for age, gender, and BMI group (model 4) models in order to accurately explore risks involved while taking age, gender, and BMI into account. Total and regional body volume parameters were converted into Z-scores to compare the study results. The Z-score was computed by subtracting the group mean value from the individual's observed value, and then dividing these subtracted values by the group sample standard deviation. 
The intra-participant reliability and the reproducibility of the body measurements assessed via SBI were evaluated by coefficients of variation over ten repeated body scans from a subset of 50 participants. Likewise, the coefficient of variation values were acquired to assure the reliability of the MRI abdominal adipose tissue data via the total abdominal, subcutaneous, and visceral adipose tissue area quantified by two trained researchers that followed standardized protocols. The coefficient of variation was computed as the ratio of standard deviation of the observed value to the mean of the observed values. Values were multiplied by 100 and reported as a percentage.

A one-way analysis of variance (ANOVA) was used to detect mean differences between different gender and BMI groups for demographic parameters and body measurements assessed via traditional anthropometrics, SBI, MRI, and ADP (Table 1 and Figures 2-4). When the results of ANOVA were significant, pairwise comparisons detected where the differences might fall by post hoc analysis of Bonferroni correction. A univariate general linear model analysis also was conducted to explore disparities of total/regional body volumes and body volume ratio parameters among different gender and BMI groups. Line graphs were created to visually examine the associations between body volume parameters and BMI classification (healthy weight, overweight, obese class I and II) (Figure 2).

Age-adjusted partial Pearson's correlation coefficients were used to describe the relationships between total/regional body volumes (torso, abdomen-hip, thigh) and upper/ lower volume ratios with a) overall obesity measures (BMI, percent body fat); and b) central obesity parameters (subcutaneous and visceral adipose tissue areas) (Table 3). Scatter plots depicting the $\mathrm{R}^{2}$ line of best fit were created to investigate linear associations between body fat percentage measured by ADP and total/regional body volumes determined via SBI, as well as visceral abdominal adipose tissue area assessed by MRI and body volume ratios acquired by SBI, according to BMI classification (Figures 3,4).

The level of significance adopted was $p<0.05$. All statistical analyses were performed by using Predictive Analytics Software Statistics 18.0 (IBM SPSS, Chicago, IL).

\section{RESULTS}

\section{Descriptive Statistics}

The general characteristics and body measurements of the subjects are shown in Table 1. The mean age, weight, height, and BMI of the overall subjects were 34.4 years, $81.6 \mathrm{~kg}$, $170.3 \mathrm{~cm}$, and $28.0 \mathrm{~kg} / \mathrm{m}^{2}$, respectively. Among the 121 participants, $35.5 \%$ had a healthy weight ( $n=24$, men; $n=19$, women), $30.6 \%$ were overweight ( $n=23$, men; $n=14$, women), $22.3 \%$ exhibited class I obesity ( $\mathrm{n}=14$, men; $\mathrm{n}=13$, women), and $11.6 \%$ showed class II obesity ( $\mathrm{n}=6$, men; $\mathrm{n}=8$, women). The BMI values for men and women in each BMI category did not differ as the group values were $22.3 \mathrm{~kg} / \mathrm{m}^{2}$ and $22.4 \mathrm{~kg} / \mathrm{m}^{2}$ in healthy, 27.7 $\mathrm{kg} / \mathrm{m}^{2}$ and $27.9 \mathrm{~kg} / \mathrm{m}^{2}$ in overweight, $32.7 \mathrm{~kg} / \mathrm{m}^{2}$ and $32.8 \mathrm{~kg} / \mathrm{m}^{2}$ in obese class I, and 37.2 $\mathrm{kg} / \mathrm{m}^{2}$ and $36.8 \mathrm{~kg} / \mathrm{m}^{2}$ in obese class II for men and women, respectively ( $\left.p>0.05\right)$. In addition, $65 \%$ were non-Hispanic white and $35 \%$ were Hispanic. In comparison to men, women possessed greater total abdominal and subcutaneous and less visceral adipose tissue areas, as determined by MRI. Only the difference in subcutaneous adipose tissue was 
statistically significant ( $p=0.01$ ). Moreover, a significantly higher percentage of total body fat assessed by ADP, as well as higher thigh volume, stereovision hip circumference, and lower-body volume ratios (thigh to total body, thigh to torso, and thigh to abdomen-hip) measured by SBI were observed in women, as opposed to men $(p<0.01)$ (Table 1). In contrast, men exhibited greater total body, torso volumes, and stereovision waist circumference than women $(p<0.01)$.

\section{Odds Ratios for Visceral Adipose Tissue Area Tertiles and Total/Regional Body Volumes and Volume Ratios}

Multinomial logistic regression analysis was conducted to predict tertiles of abdominal visceral adipose tissue depots assessed via MRI, according to total/regional body volumes and volume ratios measured by SBI. The odds ratios and $95 \%$ confidence intervals by one standard deviation increase of each parameter value for increase in visceral abdominal adipose tissue tertile are demonstrated in Table 2. Model 1 was unadjusted, model 2 was adjusted for age and gender, model 3 was adjusted for BMI group, and model 4 was adjusted for age, gender, and BMI group. Regardless of the adjustment for age and gender (model 1 and 2), higher total and regional body volumes (total body, torso, abdomen-hip), as well as upper-body volume ratios (torso to total body, abdomen-hip to total body), were associated with being in a higher visceral adipose tissue area tertile compared to lowest tertile $(p<0.01)$.

After adjusting for age and gender (model 2), as well as BMI group (model 3), torso volume and abdomen-hip volume were the strongest variables associated with increased risk for visceral adipose tissue. Among the body volume ratio parameters, the greatest decrease in the risks of having visceral adipose tissue was found with thigh to total body, thigh to abdomen-hip, and thigh to torso volume ratios $(p<0.05)$ (Table 2).

However, when the model was adjusted for age, gender, and BMI group (model 4), these associations with visceral adipose tissue were not significant ( $p>0.05)$. The exceptions were for thigh to torso and thigh to abdomen-hip volume ratios, with the odds ratios for the highest tertile compared with lowest visceral adipose tissue area tertiles being 0.44 and 0.41 , respectively $(p<0.05)$ (Table 2$)$.

\section{Reproducibility of Body Measurements}

The coefficients of variation for body measurements assessed by SBI were $0.89 \%$ for waist and $0.36 \%$ for hip circumferences; $1.16 \%$ for total body, $2.04 \%$ for torso, $1.57 \%$ for abdomen-hip, and $1.98 \%$ for thigh volumes. The coefficients of variation for total abdominal, subcutaneous, and visceral adipose tissue areas evaluated by two trained researchers were $0.69 \%, 0.83 \%$, and $0.91 \%$, respectively. These strong degrees of agreement assured the reproducibility of the body measurements assessed by SBI and MRI.

\section{Line Graphs of Body Volumes According to BMI Groups}

Differences between total and regional body volumes and volume ratios in men and women are illustrated in Figure 2, according to BMI classification. Total and regional body volumes increased, with the exception of thigh volume, in correspondence with increasing BMI classification regardless of gender (Figure 2a). Thigh volume was statistically greater for the 
obese class II group, in comparison to healthy and obese class I groups, but not between overweight and obese class II groups (Figure 2a).

Lower-body volume ratios (thigh to total body, thigh to torso, thigh to abdomen-hip) decreased according to BMI groups, specifically from healthy weight to obese class I participants (Figure 2b). No significant differences were observed between obese class I and II participants for lower-body volume ratios (thigh to total body, thigh to torso, and thigh to abdomen-hip) (Figure 2b).

\section{Scatter plots of total/regional body volumes according to overall and central obesity measures}

Figure 3 presents scatter plots of total/regional body volumes (torso, abdomen-hip, and thigh) assessed by SBI and percent body fat measured by ADP in men and women, according to BMI classifications. Total body, torso, and abdomen-hip volumes were positively correlated with percent body fat and these relationships corresponded with increasing BMI classification. Thigh volume also showed positive relationships with percent body fat (Figure 3d); however, the correlation coefficients were lower but still significant then that observed for values of other regional body volumes (Figure 3a-c). The scatter plots of visceral adipose tissue assessed by MRI and lower-body volume ratios (thigh to torso and thigh to abdomen-hip) measured by SBI, according to BMI classifications, are illustrated in Figure 4. Lower-body volume ratios showed negative associations with visceral adipose tissue that were stronger in women than men. Respective coefficient correlation values (r) for thigh to torso and thigh to abdomen-hip volume ratios were -0.73 and $-0.77(p<0.05)$ (Figure $4 \mathrm{~b}, \mathrm{~d})$ for women and -0.44 and $-0.46(p<0.05)$ for men (Figure $4 \mathrm{a}, \mathrm{c})$, respectively. Based on the visual inspection the correlation coefficients values, the scatter plots exhibited greater variations and showed attenuated correspondence with BMI groups in men, as compared to women (Figure 4a,c).

\section{Correlations between Body Volumes and Obesity Measures}

Age-adjusted partial Pearson correlation coefficients for overall/central obesity measures with total/regional body volumes and body volume ratios are presented in Table 3 . Total and regional body volumes (torso, abdomen-hip) derived from SBI were closely related with overall obesity measures (BMI and percent body fat) and subcutaneous adipose tissue. A significant, but weaker relationship was observed with visceral adipose tissue $(p<0.01)$. In contrast, thigh volume was not related to visceral adipose tissue.

In men and women, the largest negative correlations for visceral adipose tissue were observed with thigh to abdomen-hip volume ratio, clearly followed by thigh to torso volume ratio. Only women showed a significant negative relationship with thigh to total body volume ratio and visceral adipose tissue (Table 3 ). In addition, upper-body volume ratios, such as torso to total body, abdomen-hip to total body, and abdomen-hip to torso volume ratios, were positively correlated with these obesity measures (Table 3). 


\section{DISCUSSION}

The primary focus of this paper was to examine the associations between thigh volume ratios assessed by SBI and visceral adipose tissue measured by MRI. The inverse relationships of abdominal visceral adipose tissue with lower-body volume ratios reported in this study suggest that greater volumes in the lower body are more metabolically favorable than those in the upper regions. In addition, decreased visceral adipose tissue was observed with a high thigh volume in relation to abdomen-hip and torso volumes. Thus, this type of fat distribution in the lower body appears to be metabolically advantageous for both men and women.

The current investigation confirmed the favorable associations between lower body factors and accumulation of visceral adipose tissue, even after adjustment for age, gender, and BMI, as the odds ratios were 0.44 for thigh to torso volume ratio and 0.41 for thigh to abdomenhip volume ratio. It is well established that greater fat deposition in thighs or legs is believed to be a protective factor for obesity-related diseases, such as cardiovascular disease, coronary heart disease, type 2 diabetes (Heitmann and Frederiksen, 2009; Snijder et al., 2003; Seidell et al., 2001; Goodpaster et al., 2000) or longevity/mortality (Lissner et al., 2001; Heitmann and Frederiksen, 2009); whereas, fat depots in the upper portion of the body are more closely linked to those diseases. In the elderly, Snijder et al. (2003) observed that individuals with larger hip and thigh circumferences exhibited a lower risk of type 2 diabetes occurrence (Snijder et al., 2003). The odds ratios for prediction of type 2 diabetes for hip and thigh circumferences were 0.55 and 0.79 in men; and 0.63 and 0.62 in women, when adjusted for age, BMI, and waist circumference (Snijder et al., 2003). In contrast, a larger waist circumference was linked to increased incidence of developing type 2 diabetes (Snijder et al. 2003).

A study by McLaughlin et al. (2011) confirmed that thigh fat behaves as a potential protective factor, as the odds ratios for thigh fat to predict insulin resistance was 0.59 , after adjustment of gender and BMI (McLaughlin et al., 2011). Similar findings were observed in college students, with leg (but not arm) fat linked to reduction of cardiovascular risk factors $(p<0.05)$ (Sanchez-Lopez et al., 2013). In comparison, Hoyer et al. (2011) found that neither mid-thigh circumference or subcutaneous thigh adipose tissue depot was related to risk of type 2 diabetes diagnosis among Japanese Americans; the odds ratios for both were only 0.9 (Hoyer et al., 2011) ( $p>0.05)$. It is plausible that the accumulation of fat in peripheral regions of the body such as thighs, or legs, may reduce the ectopic fat accumulation in the upper body torso, which are more closely linked with metabolic risks (Manolopoulos, Karpe and Frayn, 2010). Differences in the response rate and introduction of catecholamineinduced lipolysis between gluteal and abdominal fat deposits may explain adverse effects from a physiological point of view (Wahrenberg, Lonnqvist and Arner, 1989). The reported favorable impact of lower-body factors on metabolic health may be related to an undesirable effect of inflammatory cytokines on accumulation in abdominal adiposity. In contrast, peripheral adiposity is negatively associated with systemic inflammation stimulated by cytokines (Manolopoulos et al., 2010; Tchernof and Despres, 2013). Perhaps, changes in peripheral body composition could be explained by a greater proportion of lean (muscle) mass induced by physical activity. However, Wilson et al. (2013) reported that an increased 
trunk volume, in comparison, to leg volume, was due to the elevated fat mass in each body segment, as opposed to lean mass (Wilson et al., 2013).

Wang et al. (2007) utilized a Hamamatsu photonic laser scanner to assess body volumes, including total body, trunk, arms, and legs, in class II and III obesity participants ( $\mathrm{n}=8$ men, $\mathrm{n}=23$ women). These values were compared to those with a BMI $<35 \mathrm{~kg} / \mathrm{m}^{2}$ (Wang et al., 2007). Men exhibited greater total body, torso, and arm volumes, as well as torso to total body volume ratio than women; while women had a higher leg to total body volume ratio, irrespective of BMI classifications (Wang et al., 2007). However, no differences were found in leg volume in men and women according to BMI grouping (Wang et al., 2007). The present study identified significantly greater thigh volumes in women, as compared to men. Men showed significantly higher total and upper-body volumes; whereas, women had greater values of lower-body volumes and volume ratios and these findings were consistent across BMI groups between men and women. These results correspond to the previous studies' findings that women are more prone to exhibit a gynoid body shape; whereas men are more likely to have an android body type (Haslam et al., 2006; Ludescher et al., 2009; Cornier et al., 2011).

The research by Wang et al. (2007) also observed that class II and III obese participants showed greater total body, torso, arm, leg (women only) volumes, and torso to total body volume ratio, and lower leg to total body volume ratio, as opposed to subjects with BMI < $35 \mathrm{~kg} / \mathrm{m}^{2}$ (Wang et al., 2007). Similarly, the current study observed that obesity class II subjects had greater total body, torso, abdomen-hip, and thigh volume, as opposed to other BMI groups including obesity class I, regardless of gender. In addition, thigh volumes in obese class II participants were larger than those in other BMI groups, but not significant compared to class I. This suggests that the changes in the body volume proportions were subtle among moderately and morbidly obese individuals. Greater differences may have been observed if our sample had been expanded in size or included obesity class III participants.

Wilson et al. (2013) utilized a trunk to leg volume ratio that was determined by DXA as a reflection of body shape index (Wilson et al., 2013). A higher value for this measure indicated that the proportion of trunk was greater than the legs, as the upper body volume was divided by the lower body volume. The trunk to leg volume ratio increased across underweight, healthy weight, and overweight participants $(1.40,1.46,1.57$, respectively) (Wilson et al., 2013). This investigation demonstrated that proportions of legs were larger, as compared to trunk volume for underweight individuals, and the proportion of leg volume was smaller than the trunk volume for higher BMI groups. However, no differences were found between the overweight and obese (Wilson et al., 2013). In the current study, upper body volume ratios increased according to the BMI classification, while lower body volume ratios decreased, regardless of gender. These results also conform to Wang et al. (2007) who found that lower-body volume factor (leg to total body volume ratio) decreased as BMI classification increased (Wang et al., 2007). Correspondingly, these suggest that a greater lower body volume may have a beneficial effect on being obese. Thus, as an individual progresses to a higher BMI group, body fat may be more prone to accumulate in the upper body, rather than the lower body region. 
Various types of photonic body scanners have been used previously to measure body composition and compare the body size and shape among populations as a means of clinical and field-based epidemiological assessment. The Hamamatsu Bodyline laser Scanner was validated initially in adults and children to measure body volume. It showed less than $3 \%$ of error to assess body volume compared to body volume measured by underwater weighing and ADP (Wells et al. 2000). Subsequently, a 3D photonic scanner, [TC $]^{2}$ assessed body circumferences, including head, mid-upper arm, chest, waist, hips, mid-thigh, knee, and calf among Americans, British, and Thai participants (Wells et al. 2008a, Wells, Charoensiriwath and Treleaven 2011, Wells, Treleaven and Cole 2007, Wells, Cole and Treleaven 2008b). Values of body circumference ratios, such as waist-hip, waist-chest, waist-bust, waist-thigh, thigh-arm also were explored according to different gender and age categories, with changes in body size and shape over time (Wells et al. 2007). Finally, a Chang Gung Total Body Scanner explored relationships with BMI, somatotype index and anthropometric data (Liu et al. 2001) in order to develop a health index (Lin et al. 2002, Lin et al. 2004) and chronic disease risk (Chuang et al. 2006). In this research, 3D SBI examined the total/regional body volumes and body volume ratios in terms of risks of visceral adipose tissue accumulation. The affordable cost, portability, relatively small size, and noninvasiveness of the instrument utilized in this research make it ideal for clinical or field base epidemiological studies. Its uniqueness is its ability to quantify visceral adipose tissue in a relatively simple manner, without an elaborate or bulky instrument.

A limitation of this study was the method involved with the percent fat assessment via ADP. If the whole body densities are greater than $1.10 \mathrm{~g} / \mathrm{ml}$ then negative values of body fat may result. Negative values would suggest violation of the assumption of constant density for the fat free mass. In past studies, negative values of body fat may have been considered as erroneous and perhaps, not published. However, a few studies exist that exhibit these irregular fat estimations. For example, Pollock et al. (1977) found that five runners had less than $2 \%$ predicted body fat (from density and Siri's equation). Additionally, in young men, $-0.8 \%$ and $-1.6 \%$ body fat have been predicted from fat body densities of $1.102 \mathrm{~g} / \mathrm{ml}$ (Behnke, 1963) and $1.104 \mathrm{~g} / \mathrm{ml}$ (Katch and Michael, 1968), respectively. Thus, irregular fat estimates have occurred in lean mesomorphs. It is possible that violation of the assumption of the two-compartment model equations (density constancy of $0.9 \mathrm{~kg} / \mathrm{L}$ for fat mass and 1.1 $\mathrm{kg} / \mathrm{L}$ fat-free mass) may have affected the computation of percent body fat in subjects in the current study who were very lean.

In summary, thigh volume in relation to torso and abdomen-hip volume determined by SBI were parameters that estimated the risks of possessing visceral adipose tissue, the metabolically active fat depot. Favorable effects of lower-body components on visceral fat were observed in both men and women, despite gender differences in body size and shape.

\section{Acknowledgments}

Supported by: NIH R21 DK081206

This research was supported by grant R21 DK081206 from the National Institutes of Health. Jane J Lee collected the research data and proceeded with data analysis, and composed the initial manuscript. Jeanne H Freeland-Graves served as the primary investigator and prepared the manuscript. M Reese Pepper implemented the study and participated in data collection. Wurong $\mathrm{Yu}$ and Bugao $\mathrm{Xu}$ developed the three-dimensional stereovision imaging 
system and the volume measurement software. Bugao Xu served as one of the Principal Investigators for the NIH grants and provided the training and support for SBI data collection and processing.

\section{References}

Aasen G, Fagertun H, Tonstad S, Halse J. Leg fat mass as measured by dual X-ray absorptiometry (DXA) impacts insulin resistance differently in obese women versus men. Scand J Clin Lab Invest. 2009; 69:181-189. [PubMed: 18937100]

Behnke AR. Anthropometric Evaluation of Body Composition Throughout Life. Ann N Y Acad Sc. 1963; 110:450-464. [PubMed: 14061658]

Bergman RN, Stefanovski D, Buchanan TA, Sumner AE, Reynolds JC, Sebring NG, Xiang AH, Watanabe RM. A better index of body adiposity. Obesity (Silver Spring). 2011; 19:1083-1089. [PubMed: 21372804]

Brožek J, Grande F, Anderson JT, Keys A. Densitometric analysis of body composition: revision of some quantitative assumptions. Ann N Y Acad Sci. 1961; 110:113-40. [PubMed: 14062375]

Chuang YC, Wang MH, Huang DH, Yang CH, Lin JD. To construct a forecasting model of the anthropometric chronic disease risk factor score. Chang Gung Med J. 2006; 29:135-42. [PubMed: 16767961]

Collins AL, Saunders S, McCarthy HD, Williams JD, Fuller NJ. Within- and between-laboratory precision in the measurement of body volume using air displacement plethysmography and its effect on body composition assessment. Int J Obes Relat Metab Disord. 2004; 28:80-90. [PubMed: 14710169]

Cornier MA, Despres JP, Davis N, Grossniklaus DA, Klein S, Lamarche B, Lopez-Jimenez F, Rao G, St-Onge MP, Towfighi A, Poirier P. Assessing adiposity: a scientific statement from the American Heart Association. Circulation. 2011; 124:1996-2019. [PubMed: 21947291]

Despres JP, Lemieux I. Abdominal obesity and metabolic syndrome. Nature. 2006; 444:881-887. [PubMed: 17167477]

Despres JP, Lemieux I, Bergeron J, Pibarot P, Mathieu P, Larose E, Rodes-Cabau J, Bertrand OF, Poirier P. Abdominal obesity and the metabolic syndrome: contribution to global cardiometabolic risk. Arterioscler Thromb Vasc Biol. 2008; 28:1039-1049. [PubMed: 18356555]

Fox CS, Massaro JM, Hoffmann U, Pou KM, Maurovich-Horvat P, Liu CY, Vasan RS, Murabito JM, Meigs JB, Cupples LA, D’Agostino RB, O’Donnell CJ. Abdominal visceral and subcutaneous adipose tissue compartments: association with metabolic risk factors in the Framingham Heart Study. Circulation. 2007; 116:39-48. [PubMed: 17576866]

Franssen R, Monajemi H, Stroes ES, Kastelein JJ. Obesity and dyslipidemia. Med Clin North Am. 2011; 95:893-902. [PubMed: 21855698]

Goodpaster BH, Thaete FL, Kelley DE. Thigh adipose tissue distribution is associated with insulin resistance in obesity and in type 2 diabetes mellitus. Am J Clin Nutr. 2000; 71:885-892. [PubMed: 10731493]

Haarbo J, Marslew U, Gotfredsen A, Christiansen C. Postmenopausal hormone replacement therapy prevents central distribution of body fat after menopause. Metabolism. 1991; 40:1323-1326. [PubMed: 1961129]

Haslam D, Sattar N, Lean M. ABC of obesity. Obesity-time to wake up. BMJ. 2006; 333:640-642. [PubMed: 16990325]

Hayashi T, Boyko EJ, McNeely MJ, Leonetti DL, Kahn SE, Fujimoto WY. Visceral adiposity, not abdominal subcutaneous fat area, is associated with an increase in future insulin resistance in Japanese Americans. Diabetes. 2008; 57:1269-1275. [PubMed: 18299316]

Heitmann BL, Frederiksen P. Thigh circumference and risk of heart disease and premature death: prospective cohort study. BMJ. 2009; 339:b3292. [PubMed: 19729416]

Hoyer D, Boyko EJ, McNeely MJ, Leonetti DL, Kahn SE, Fujimoto WY. Subcutaneous thigh fat area is unrelated to risk of type 2 diabetes in a prospective study of Japanese Americans. Diabetologia. 2011; 54:2795-2800. [PubMed: 21837509]

Kanaley JA, Sames C, Swisher L, Swick AG, Ploutz-Snyder LL, Steppan CM, Sagendorf KS, Feiglin D, Jaynes EB, Meyer RA, Weinstock RS. Abdominal fat distribution in pre- and postmenopausal 
women: The impact of physical activity, age, and menopausal status. Metabolism. 2001; 50:976982. [PubMed: 11474488]

Katch FI, Michael ED. Prediction of body dentisty from skin-fold and girth measurements of college females. J Appl Physiol. 1968; 25:92-94. [PubMed: 5661158]

Kurukulasuriya LR, Stas S, Lastra G, Manrique C, Sowers JR. Hypertension in obesity. Med Clin North Am. 2011; 95:903-917. [PubMed: 21855699]

Lee JJ, Freeland-Graves JH, Pepper MR, Yao M, Xu B. Predictive equations for central obesity via anthropometrics, stereovision imaging and MRI in adults. Obesity (Silver Spring). 2014; 22:852862. [PubMed: 23613161]

Lin JD, Chiou WK, Weng HF, Fang JT, Liu TH. Application of three-dimensional body scanner: observation of prevalence of metabolic syndrome. Clin Nutr. 2004; 23:1313-23. [PubMed: 15556253]

Lin JD, Chiou WK, Weng HF, Tsai YH, Liu TH. Comparison of three-dimensional anthropometric body surface scanning to waist-hip ratio and body mass index in correlation with metabolic risk factors. J Clin Epidemiol. 2002; 55:757-66. [PubMed: 12384189]

Lissner L, Bjorkelund C, Heitmann BL, Seidell JC, Bengtsson C. Larger hip circumference independently predicts health and longevity in a Swedish female cohort. Obes Res. 2001; 9:644646. [PubMed: 11595782]

Liu TH, Chiou WK, Lin JD, Yu CY. Implementation of whole body scanner for determining somatotype index at Chang Gung Memorial Hospital. Chang Gung Med J. 2001; 24:697-707. [PubMed: 11820650]

Lohman TG. Assessment of body composition in children. Pediatr Exerc Sci. 1986; 1:19-30.

Logue J, Murray HM, Welsh P, Shepherd J, Packard C, Macfarlane P, Cobbe S, Ford I, Sattar N. Obesity is associated with fatal coronary heart disease independently of traditional risk factors and deprivation. Heart. 2011; 97:564-568. [PubMed: 21324888]

Ludescher B, Machann J, Eschweiler GW, Vanhofen S, Maenz C, Thamer C, Claussen CD, Schick F. Correlation of fat distribution in whole body MRI with generally used anthropometric data. Invest Radiol. 2009; 44:712-719. [PubMed: 19809346]

Manolopoulos KN, Karpe F, Frayn KN. Gluteofemoral body fat as a determinant of metabolic health. Int J Obes (Lond). 2010; 34:949-959. [PubMed: 20065965]

Massey FJ Jr. The Kolmogorov-Smirnov test for goodness of fit. Journal of the American statistical Association. 1951; 46:68-78.

McLaughlin T, Lamendola C, Liu A, Abbasi F. Preferential fat deposition in subcutaneous versus visceral depots is associated with insulin sensitivity. J Clin Endocrinol Metab. 2011; 96:E17561760. [PubMed: 21865361]

National Center for Health Statistics. Health, United States, 2012: With Special Feature on Emergency Care. Hyattsville, MD: 2013.

National Health and Nutrition Examination Survey III, Body Measurements (Anthropometry). Westat: 1988.

Nguyen NT, Nguyen XM, Lane J, Wang P. Relationship between obesity and diabetes in a US adult population: findings from the National Health and Nutrition Examination Survey, 1999-2006. Obes Surg. 2011; 21:351-355. [PubMed: 21128002]

Ortiz O, Russell M, Daley TL, Baumgartner RN, Waki M, Lichtman S, Wang J, Pierson RN, Heymsfield SB. Differences in skeletal muscle and bone mineral mass between black and white females and their relevance to estimates of body composition. Am J Clin Nutr. 1992; 55:8-13. [PubMed: 1728823]

Park JS, Cho MH, Ahn CW, Kim KR, Huh KB. The association of insulin resistance and carotid atherosclerosis with thigh and calf circumference in patients with type 2 diabetes. Cardiovasc Diabetol. 2012; 11:62. [PubMed: 22682537]

Peppa M, Koliaki C, Hadjidakis DI, Garoflos E, Papaefstathiou A, Katsilambros N, Raptis SA, Dimitriadis GD. Regional fat distribution and cardiometabolic risk in healthy postmenopausal women. Eur J Intern Med. 2013; 24:824-831. [PubMed: 24169066]

Polloc ML, Gettman LR, Jackson A, Ayres J, Ward A, Linnerud AC. Body composition of elite class distance runners. Ann N Y Acad Sci. 1977; 301:361-370. [PubMed: 270927] 
Preis SR, Massaro JM, Robins SJ, Hoffmann U, Vasan RS, Irlbeck T, Meigs JB, Sutherland P, D'Agostino RB Sr, O'Donnell CJ, Fox CS. Abdominal subcutaneous and visceral adipose tissue and insulin resistance in the Framingham heart study. Obesity (Silver Spring). 2010; 18:21912198. [PubMed: 20339361]

Reubinoff BE, Wurtman J, Rojansky N, Adler D, Stein P, Schenker JG, Brzezinski A. Effects of hormone replacement therapy on weight, body composition, fat distribution, and food intake in early postmenopausal women: a prospective study. Fertil Steril. 1995; 64:963-968. [PubMed: 7589642]

Sanchez-Lopez M, Ortega FB, Moya-Martinez P, Lopez-Martinez S, Ortiz-Galeano I, Gomez-Marcos MA, Sjostrom M, Martinez-Vizcaino V. Leg fat might be more protective than arm fat in relation to lipid profile. Eur J Nutr. 2013; 52:489-495. [PubMed: 22484387]

Schutte JE, Townsend EJ, Hugg J, Shoup RF, Malina RM, Blomqvist CG. Density of lean body mass is greater in blacks than whites. J Appl Physiol. 1984; 56:1647-1649. [PubMed: 6735823]

Seidell JC, Perusse L, Despres JP, Bouchard C. Waist and hip circumferences have independent and opposite effects on cardiovascular disease risk factors: the Quebec Family Study. Am J Clin Nutr. 2001; 74:315-321. [PubMed: 11522554]

Siri, WE. Body composition from fluid spaces and density: analysis of methods. In: Brožek, J.; Henschel, A., editors. Techniques for measuring body composition. Washington DC: Natl AcadSciences/Natl Res Council; 1961. p. 223-24.

Smith DA, Ness EM, Herbert R, Schechter CB, Phillips RA, Diamond JA, Landrigan PJ. Abdominal diameter index: a more powerful anthropometric measure for prevalent coronary heart disease risk in adult males. Diabetes Obes Metab. 2005; 7:370-380. [PubMed: 15955123]

Snijder MB, Dekker JM, Visser M, Bouter LM, Stehouwer CD, Kostense PJ, Yudkin JS, Heine RJ, Nijpels G, Seidell JC. Associations of hip and thigh circumferences independent of waist circumference with the incidence of type 2 diabetes: the Hoorn Study. Am J Clin Nutr. 2003; 77:1192-1197. [PubMed: 12716671]

Snijder MB, Dekker JM, Visser M, Bouter LM, Stehouwer CD, Yudkin JS, Heine RJ, Nijpels G, Seidell JC. Trunk fat and leg fat have independent and opposite associations with fasting and postload glucose levels: the Hoorn study. Diabetes Care. 2004; 27:372-377. [PubMed: 14747216]

Tchernof A, Despres JP. Pathophysiology of human visceral obesity: an update. Physiol Rev. 2013; 93:359-404. [PubMed: 23303913]

Toth MJ, Tchernof A, Sites CK, Poehlman ET. Effect of menopausal status on body composition and abdominal fat distribution. Int J Obes Relat Metab Disord. 2000; 24:226-231. [PubMed: 10702775]

Van Pelt RE, Evans EM, Schechtman KB, Ehsani AA, Kohrt WM. Contributions of total and regional fat mass to risk for cardiovascular disease in older women. Am J Physiol Endocrinol Metab. 2002; 282:E1023-1028. [PubMed: 11934666]

Van Pelt RE, Jankowski CM, Gozansky WS, Schwartz RS, Kohrt WM. Lower-body adiposity and metabolic protection in postmenopausal women. J Clin Endocrinol Metab. 2005; 90:4573-4578. [PubMed: 15886255]

Wahrenberg H, Lonnqvist F, Arner P. Mechanisms underlying regional differences in lipolysis in human adipose tissue. J Clin Invest. 1989; 84:458-467. [PubMed: 2503539]

Wang J, Gallagher D, Thornton JC, Yu W, Weil R, Kovac B, Pi-Sunyer FX. Regional body volumes, BMI, waist circumference, and percentage fat in severely obese adults. Obesity (Silver Spring). 2007; 15:2688-2698. [PubMed: 18070760]

Wells JC, Charoensiriwath S, Treleaven P. Reproduction, aging, and body shape by three-dimensional photonic scanning in Thai men and women. Am J Hum Biol. 2011; 23:291-298. [PubMed: 21387458]

Wells JC, Cole TJ, Bruner D, Treleaven P. Body shape in American and British adults: betweencountry and inter-ethnic comparisons. Int J Obes (Lond). 2008a; 32:152-159. [PubMed: 17667912]

Wells JC, Cole TJ, Bruner D, Treleaven P. Age-variability in body shape associated with excess weight: the UK National Sizing Survey. Obesity (Silver Spring). 2008b; 16:435-441. [PubMed: 18239656] 
Wells JC, Douros I, Fuller NJ, Elia M, Dekker L. Assessment of body volume using three-dimensional photonic scanning. Ann N Y Acad Sci. 2000; 904:247-254. [PubMed: 10865749]

Wells JC, Treleaven P, Cole TJ. BMI compared with 3-dimensional body shape: the UK National Sizing Survey. Am J Clin Nutr. 2007; 85:419-425. [PubMed: 17284738]

Wilson JP, Kanaya AM, Fan B, Shepherd JA. Ratio of trunk to leg volume as a new body shape metric for diabetes and mortality. PLoS One. 2013; 8:e68716. [PubMed: 23874736]

Xu B, Yu W, Yao M, Pepper MR, Freeland-Graves JH. Three-dimensional surface imaging system for assessing human obesity. Opt Eng. 2009; 48:nihpa156427. [PubMed: 19966948]

$\mathrm{Yu}$ W, Xu B. A Portable Stereo Vision System for Whole Body Surface Imaging. Image Vis Comput. 2010; 28:605-613. [PubMed: 20161620] 
(a) Men, BMI $20 \mathrm{~kg} / \mathrm{m}^{2}$, healthy weight
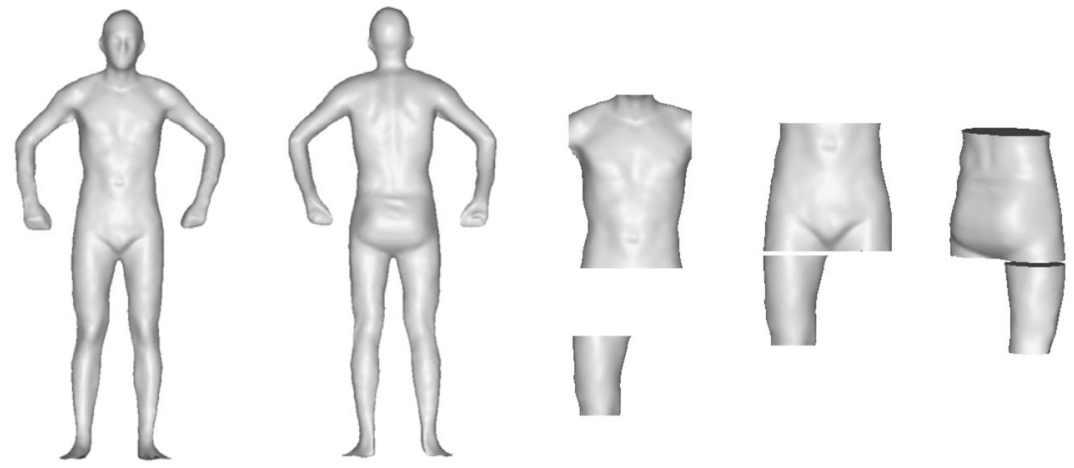

(b) Men, BMI $26 \mathrm{~kg} / \mathrm{m}^{2}$, Overweight
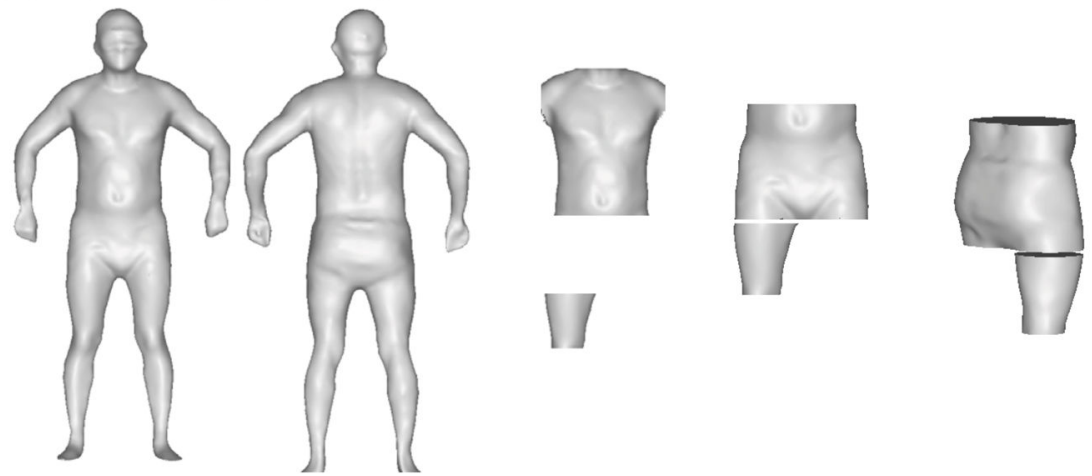

(c) Men, BMI $31 \mathrm{~kg} / \mathrm{m}^{2}$, obese class I

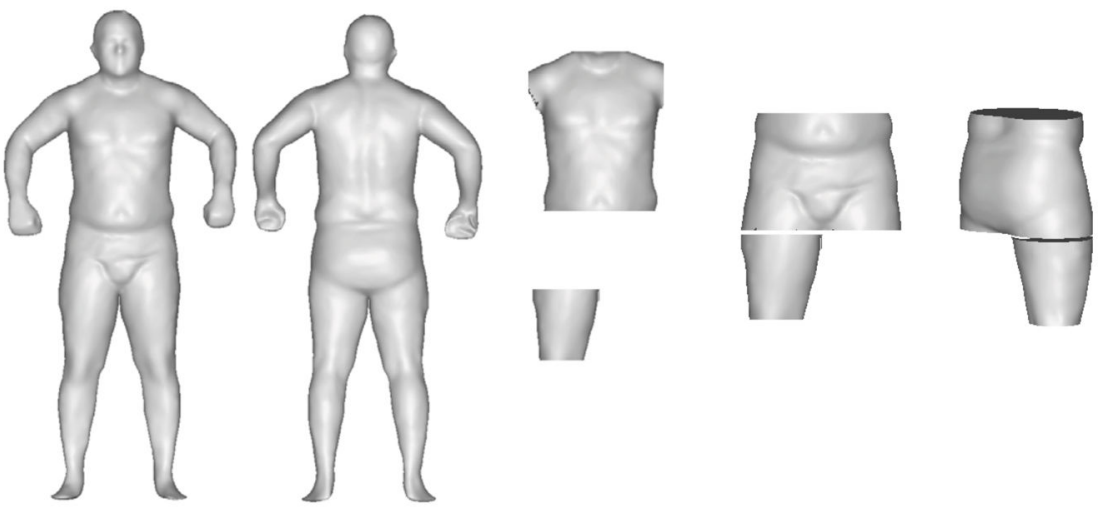


(d) Men, BMI $40 \mathrm{~kg} / \mathrm{m}^{2}$, obese class II
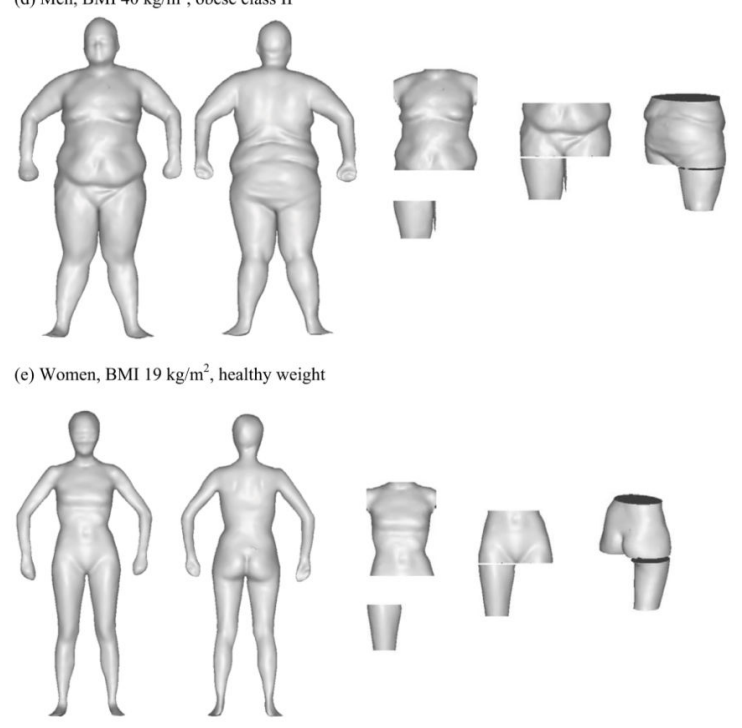

(f) Women, BMI $25 \mathrm{~kg} / \mathrm{m}^{2}$, overweight

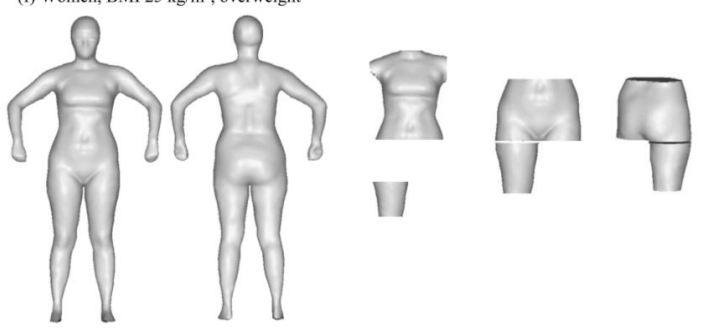


(e) Women, BMI $30 \mathrm{~kg} / \mathrm{m}^{2}$, obese class I
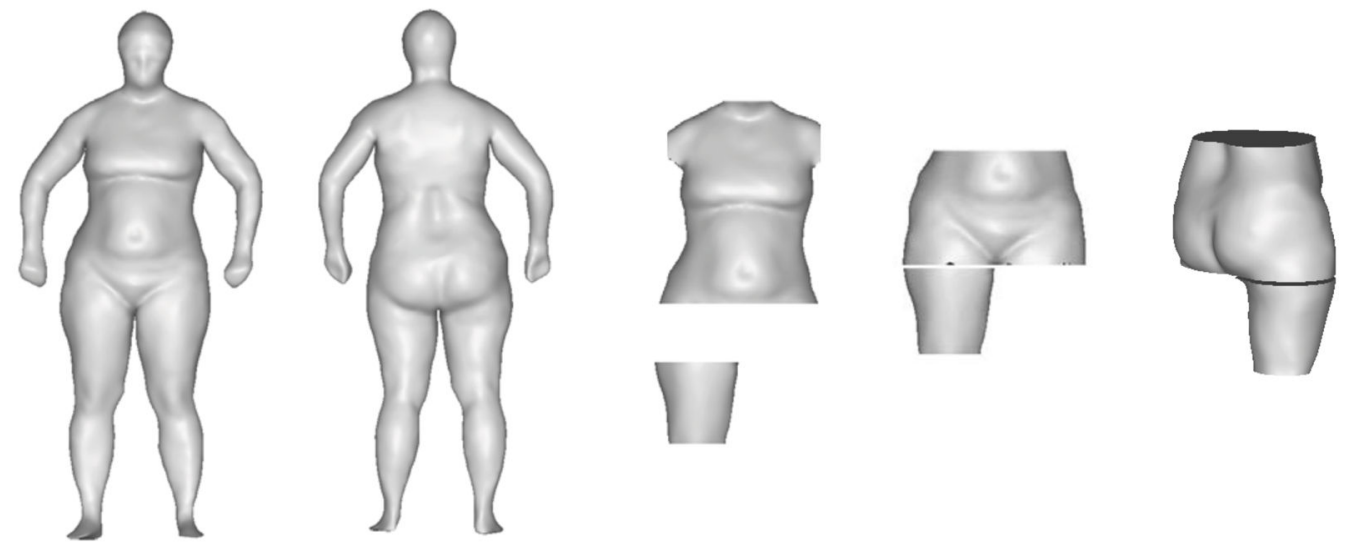

(f) Women, BMI $40 \mathrm{~kg} / \mathrm{m}^{2}$, obese class II

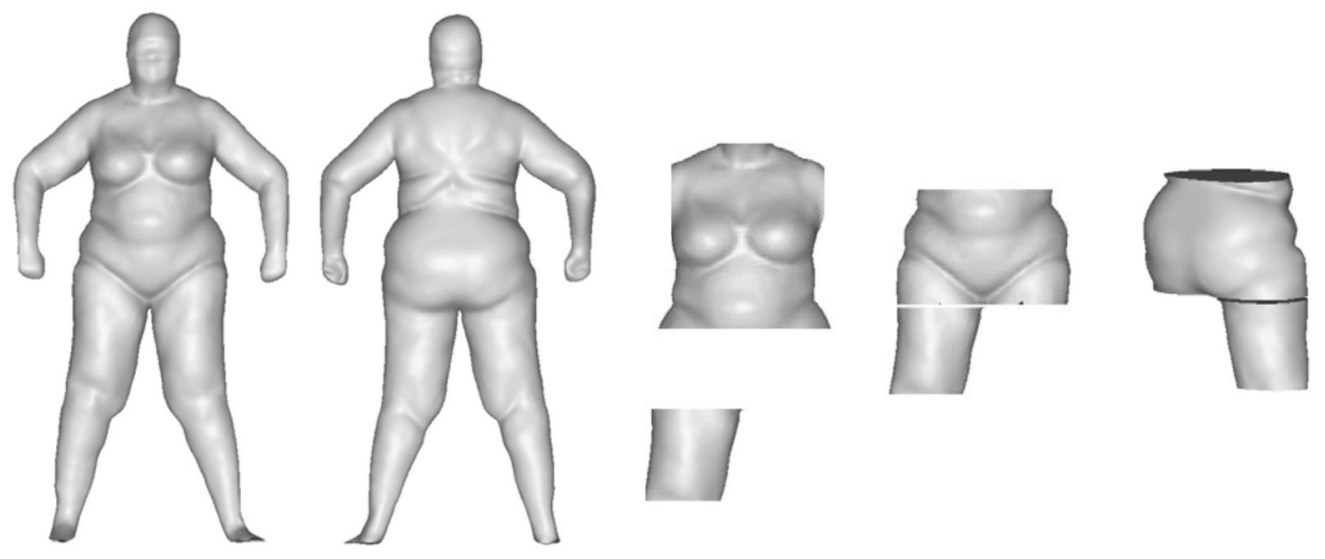

Figure 1.

Total and regional body volumes according to BMI classification assessed by a stereovision body imaging system. Left to right: front of total body volume, back of total body volume, front of torso and thigh volums, front of abdomen-hip and thigh volumes, and back of abdomen-hip and thigh volumes. 

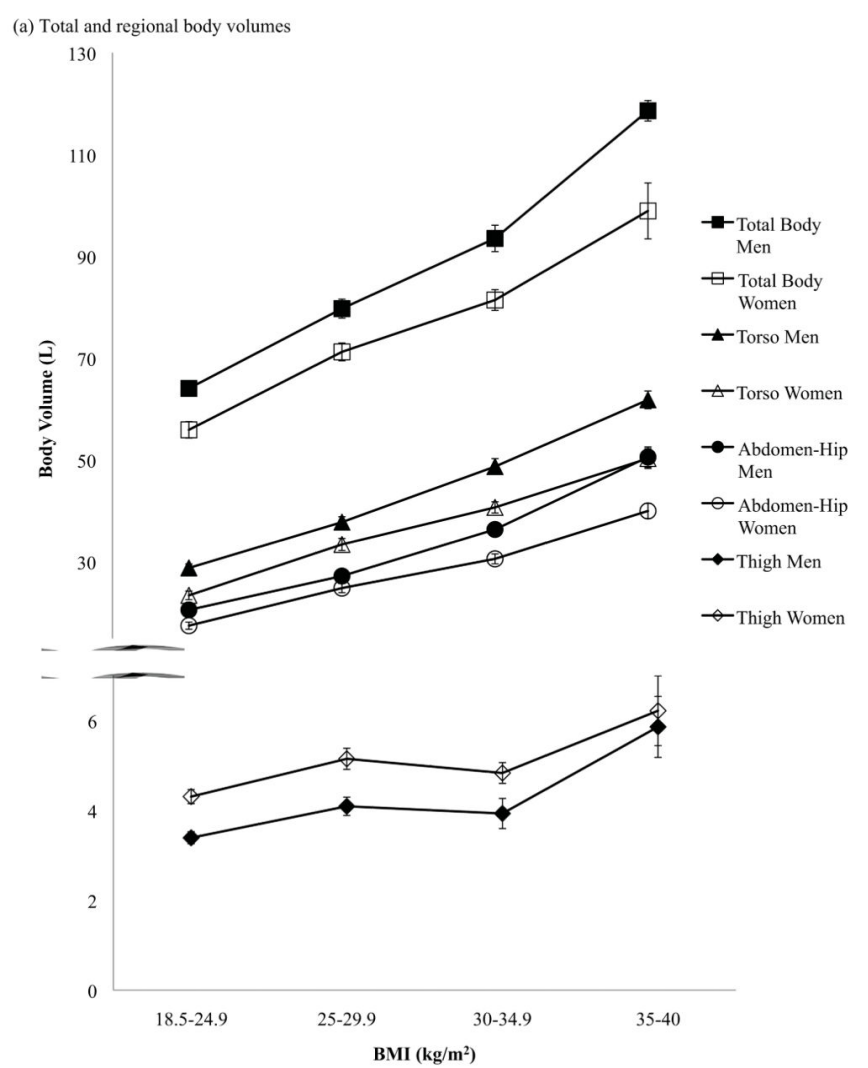


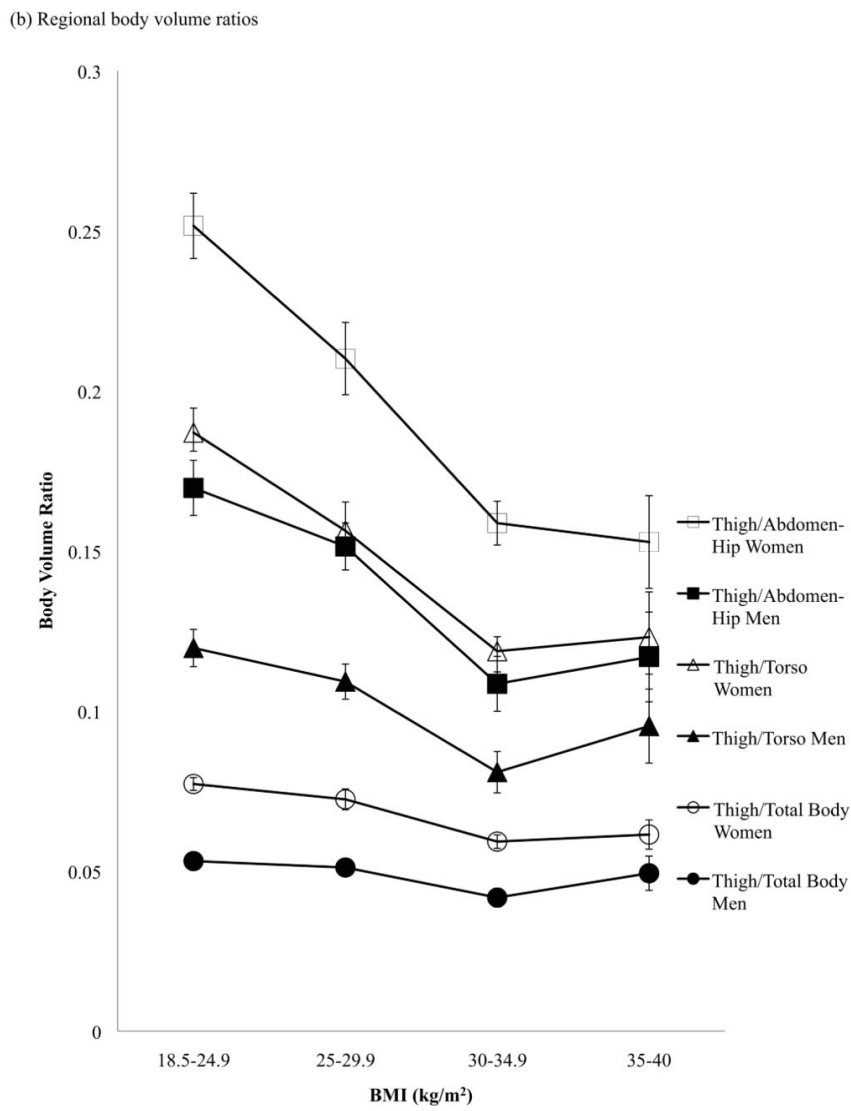

Figure 2.

Total and regional body volumes and body volume ratios of men and women assessed by stereovision body imaging, according to BMI classification. 
(a)

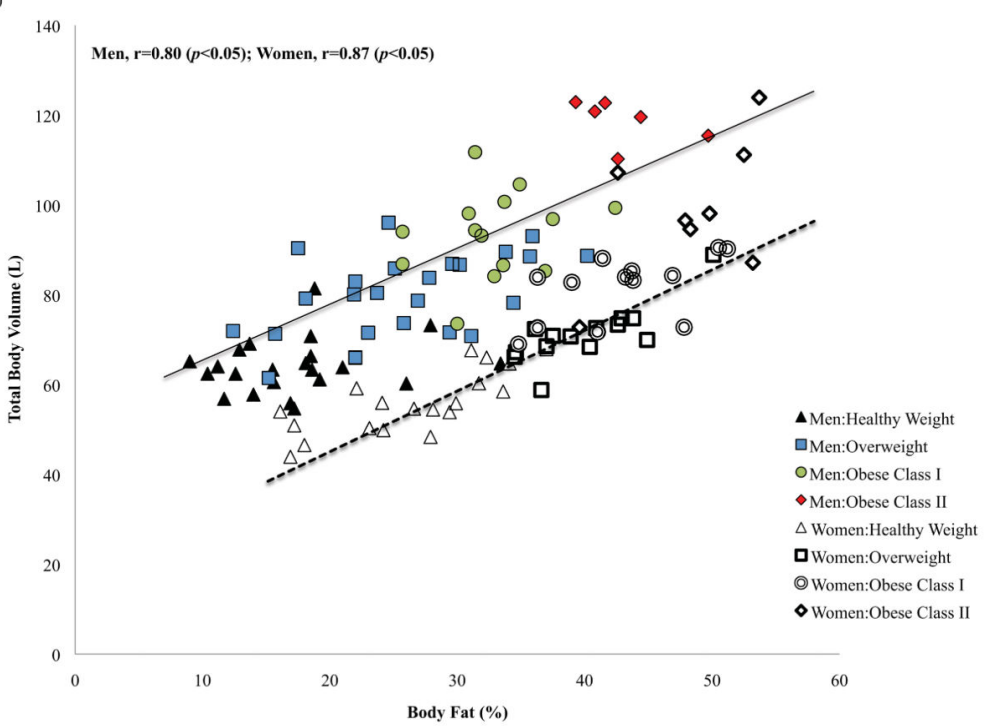

(b)

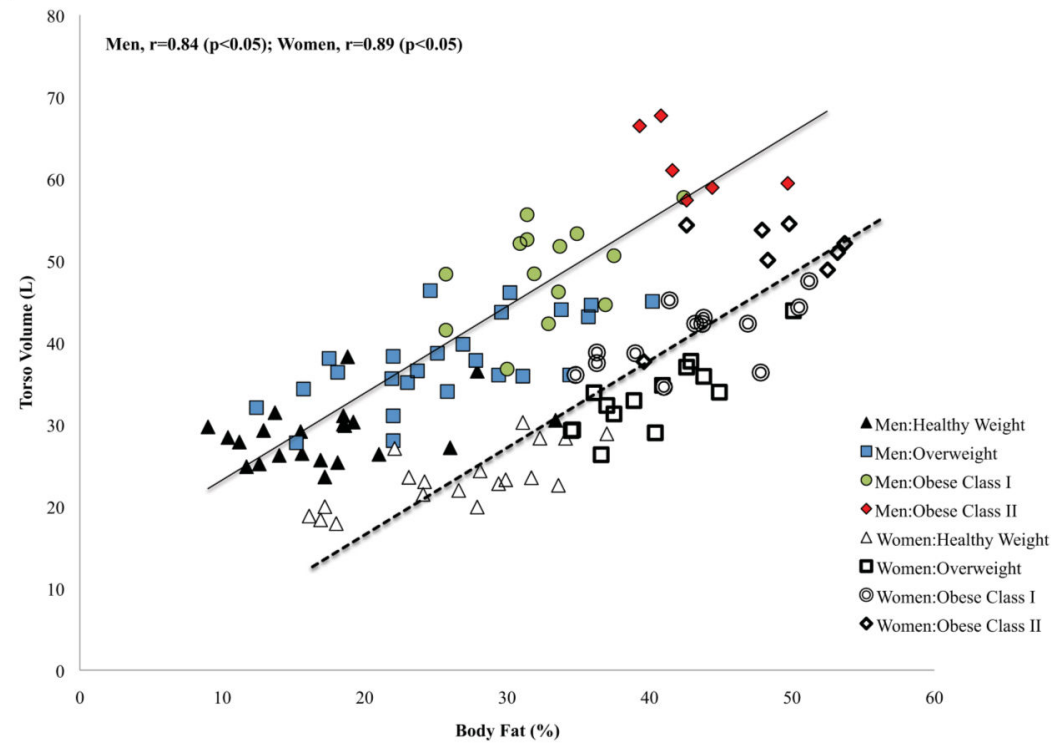

Am J Hum Biol. Author manuscript; available in PMC 2016 July 08. 
(c)

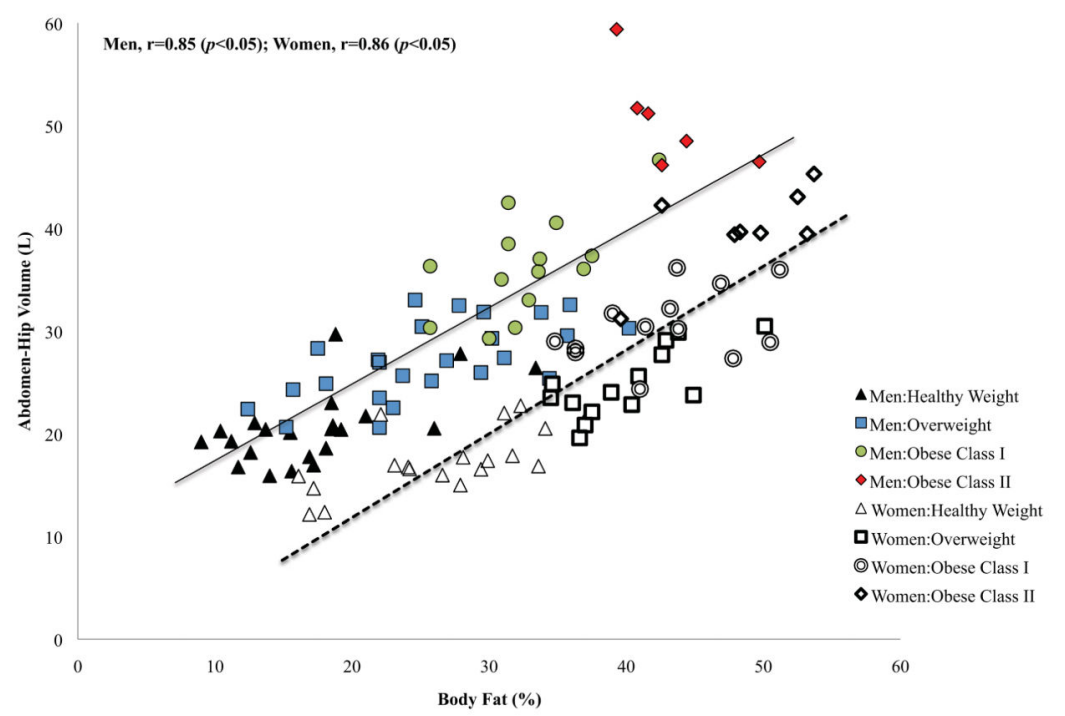

(d)

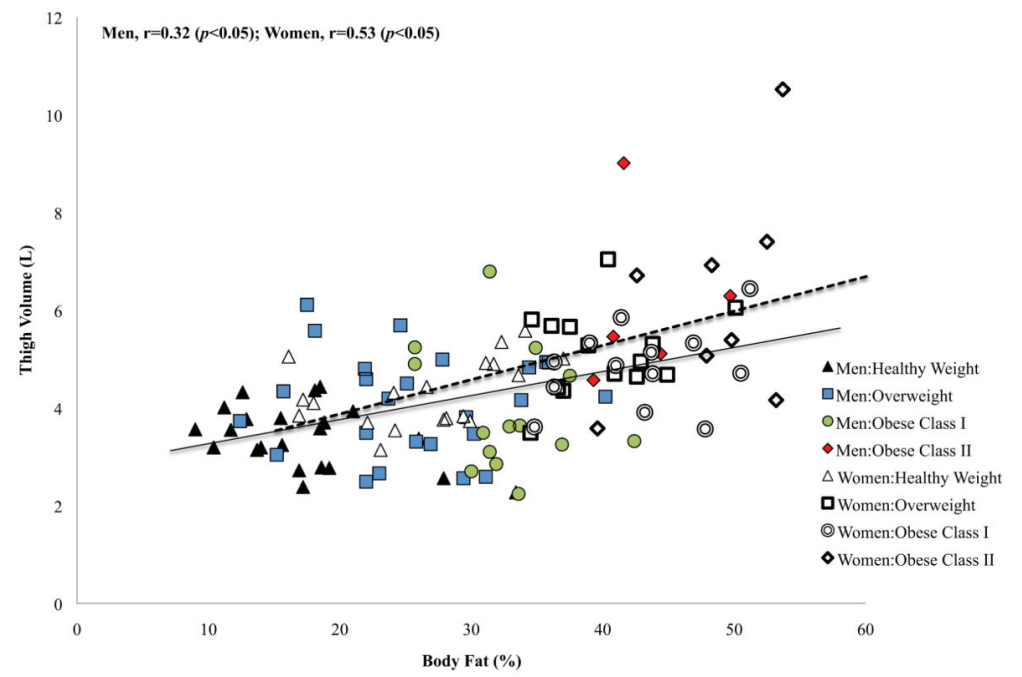

Figure 3.

Scatter plots of total/regional body volumes assessed by stereovision body imaging and percent body fat measured by air displacement plethysmography in men and women, according to BMI classifications.

(a) Total body volume according to $\%$ body fat

(b) Torso volume according to \% body fat

(c) Abdomen-hip volume according to \% body fat

(d) Thigh volume according to $\%$ body fat 
(a)

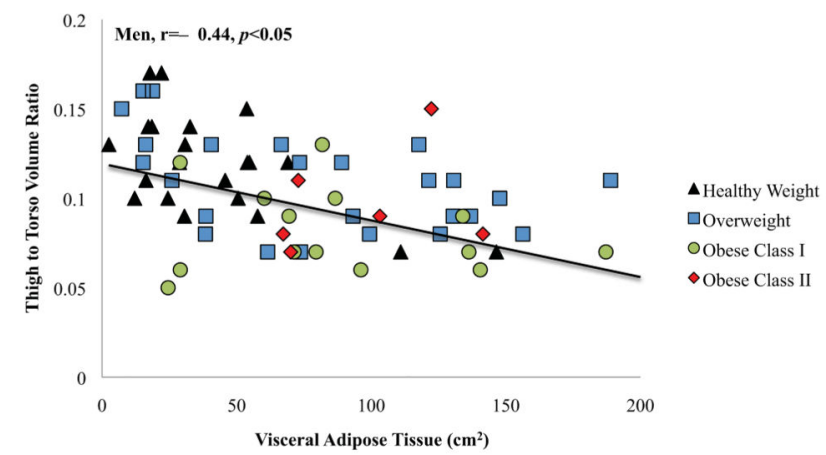

(b)

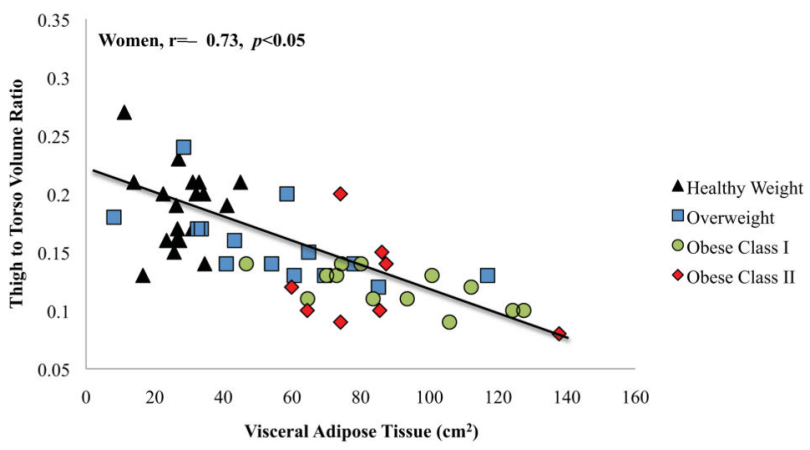




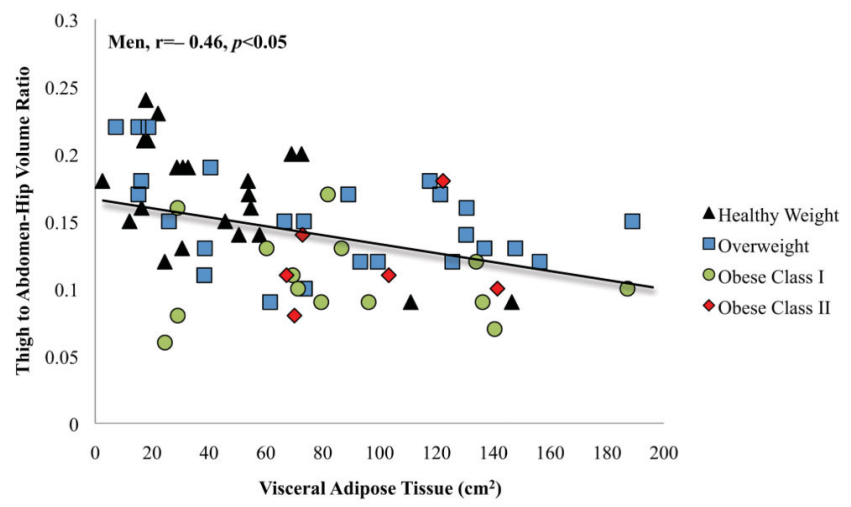

(d)

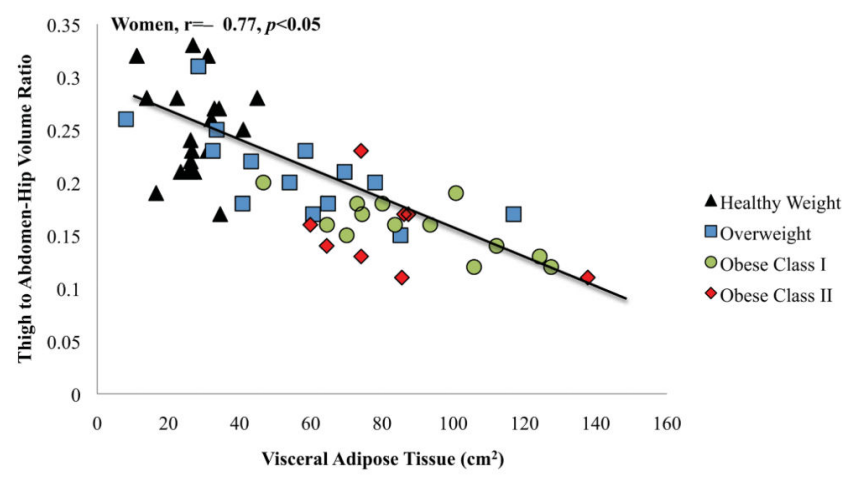

Figure 4.

Scatter plots of visceral adipose tissue assessed by magnetic resonance imaging according to lower-body volume ratios measured by stereovision body imaging in men and women, according to BMI classifications.

(a) Visceral adipose tissue according to thigh to torso volume ratio in men

(b) Visceral adipose tissue according to thigh to torso volume ratio in women

(c) Visceral adipose tissue according to thigh to abdomen-hip volume ratio in men

(d) Visceral adipose tissue according to thigh to abdomen-hip volume ratio in women 


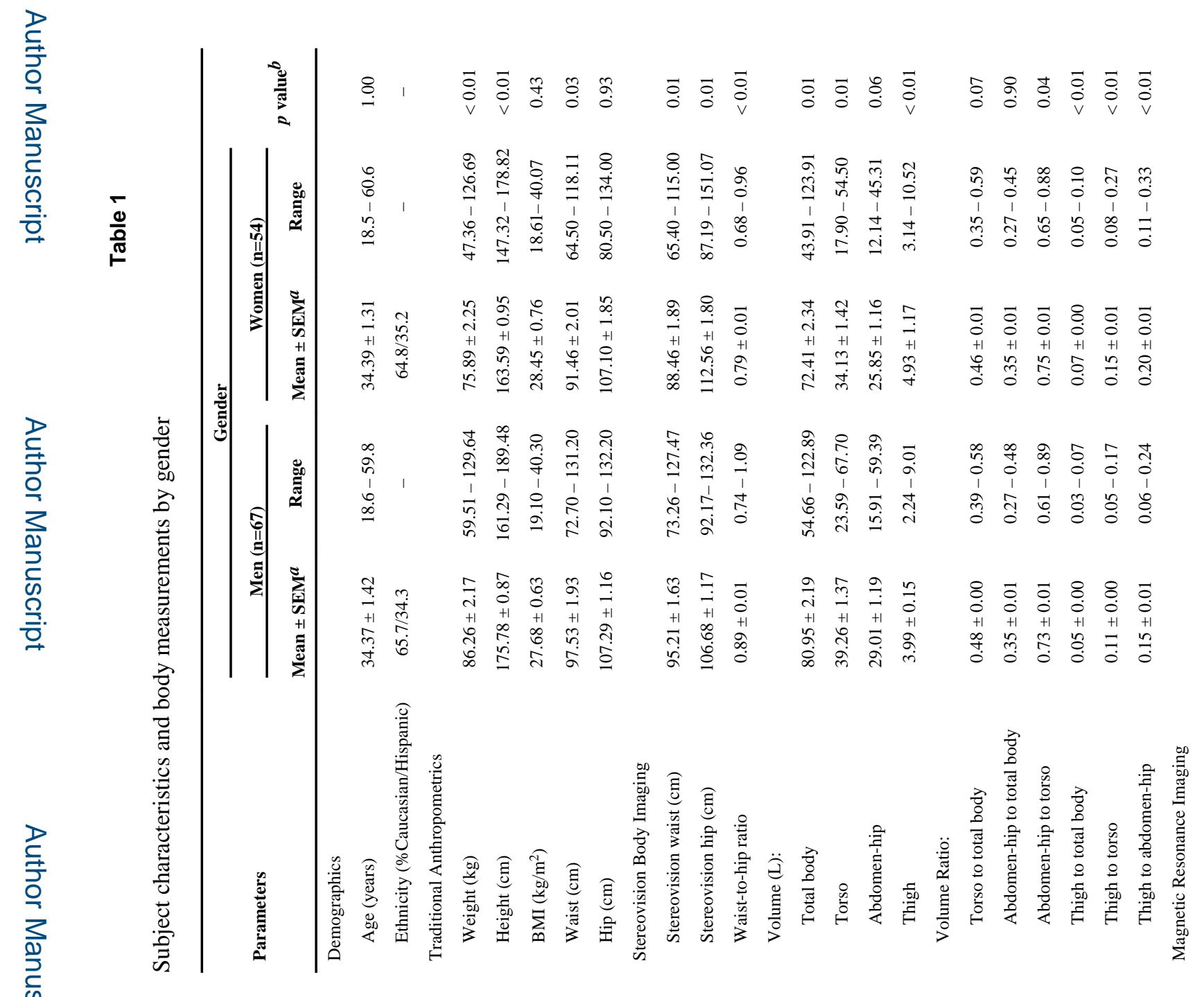

Am J Hum Biol. Author manuscript; available in PMC 2016 July 08. 


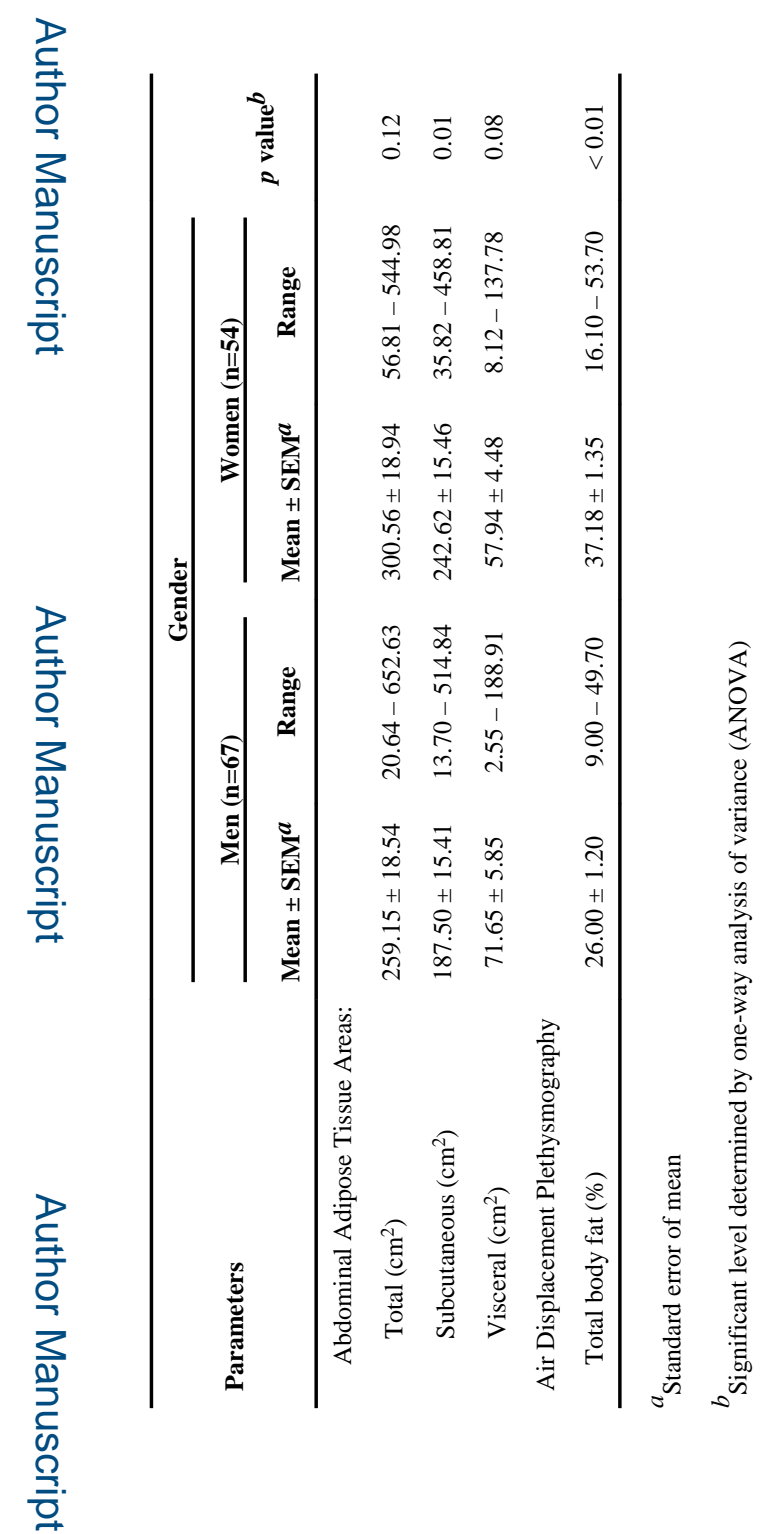

Am J Hum Biol. Author manuscript; available in PMC 2016 July 08. 


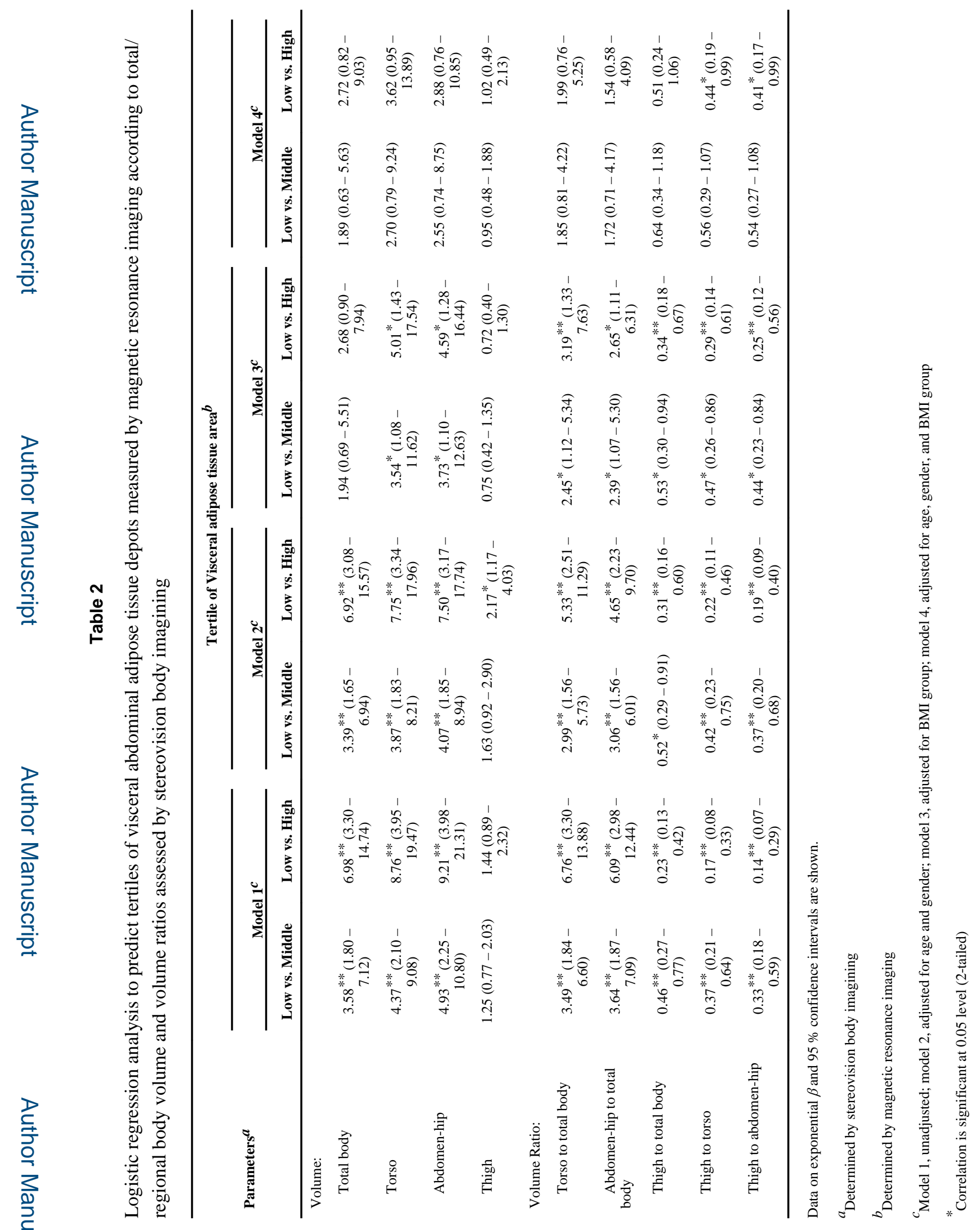

Am J Hum Biol. Author manuscript; available in PMC 2016 July 08. 


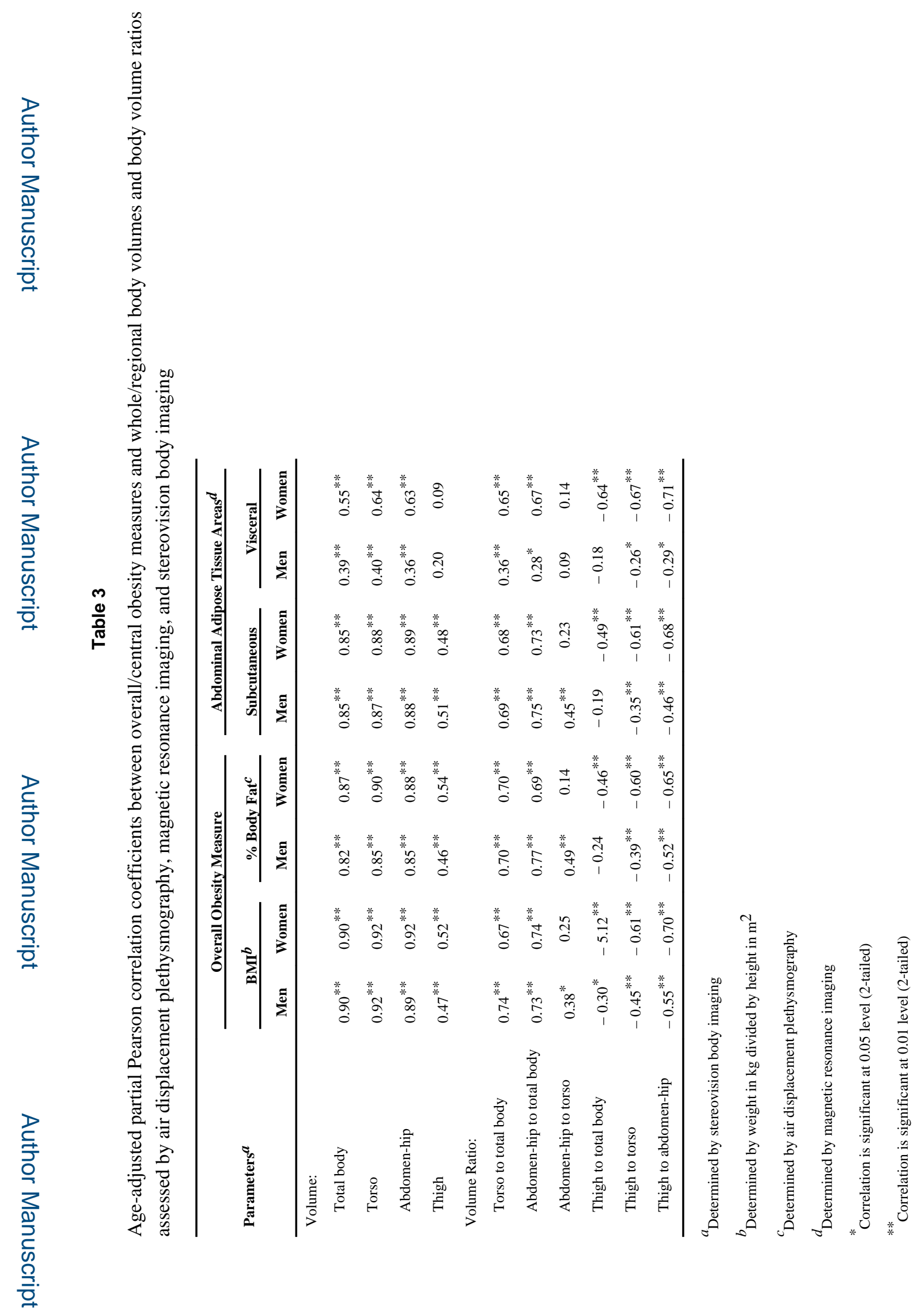

Am J Hum Biol. Author manuscript; available in PMC 2016 July 08. 